\title{
PENINGKATAN KEMAMPUAN PESERTA DIDIK KELAS IV SD NEGERI 2 WATES KULON PROGO SEMESTER I TAHUN PELAJARAN 2018/2019 DALAM MENYEBUTKAN NAMA DAN TUGAS MALAIKAT ALLAH MENGGUNAAN METODE SMART GAMES
}

\author{
Fatkiyah \\ SDN 2 Wates Kulon Progo \\ fatkiyah2020@gmail.com
}

\begin{abstract}
The success of the teaching and learning process in the classroom is determined by the learning strategy. Without being implemented through the right strategy, the components of teaching and learning process will not have meaning in achieving goals. Therefore, each teacher will be required to implement certain strategies or methods in the implementation of learning. The aim of this study is to improve thinking skills of the student achievement after the implementation of learning strategies. This research uses action research as much as three rounds. Each round consists of four stages: design, activity and observation, reflection, and refinement. The targets of this study were grade IV students. The data obtained were in the form of test results, observational sheets of teaching and learning activities. From the results of the analyst found that student achievement has increased from cycle I to cycle III namely, cycle I (68.00\%), cycle II (80.00\%), cycle III (92.00\%). The conclusion of this research is the smart games method and the make a match type of cooperative learning can have a positive effect on student learning motivation, and this learning model can be used as an alternative to PAI learning.
\end{abstract}

Keywords: Smart Games, Increasing Student Ability, Names and Duties of Angels of Allah 


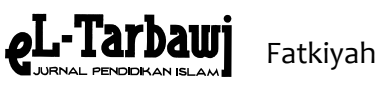

\section{Pendahuluan}

Pendidikan agama yang diselenggarakan secara inspiratif, interaktif, menantang, menyenangkan, serta mendorong kreativitas dan kemandirian, juga menumbuhkan motivasi hidup sukses. Dengan pendidikan agama sebagai pendidikan yang mentransfer pengetahuan dan membentuk sikap, kepribadian dan keterampilan peserta didik dalam hal mengamalkan ajaran agama, yang dilaksanakan sekurangkurangnya melalui mata pelajaran atau mata kuliah pada semua jalur, jenjang, dan jenis pendidikan. Hal tersebut termaktub dalam Peraturan Pemerintah Nomor 55 Tahun 2007 tentang Pendidikan Agama dan Keagamaan pada pasal 5 ayat 1-7. Sedangkan pada peraturan lain, berkaitan dengan pelaksanaan kegiatan inti, pembelajaran dilaksanakan secara inspiratif, interaktif, menantang, menyenangkan, memotivasi perserta didik untuk berpartisipasi aktif, dan memberikan ruang bagi kreativitas, prakarsa, dan kemandirian sesuai bakat, minat dan perkembangan fisik serta psikologis peserta didik. Hal tersebut tercantum dalam Peraturan Menteri Pendidikan dan Kebudayaan Nomor 22 Tahun 2016 terkait Standar Proses Untuk Satuan Pendidikan Dasar dan Menengah.

Pelaksanaan kegiatan inti dapat menggunakan berbagai metode dengan menyesuaikan karakteristik peserta didik atau mata pelajaran dengan proses elaborasi, eksplorasi, dan konfirmasi. Pada fase eksplorasi, guru seyogyanya memfasilitasi segala interaksi yang terjadi di dalam kelas, baik interaksi peserta didik dengan peserta didik yang lain atau dengan guru, lingkungan atau dengan sumber belajar yang lain. Hal ini menjadikan peserta didik terlibat secara aktif dalam proses KBM (Kegiatan Belajar Mengajar). Sedangkan pada fase elaborasi, guru dapat memberikan fasilitas kepada peserta didik dalam untuk mendukung pembelajaran yang kooperatif dan kolaboratif, memberikan fasilitas agar peserta didik mampu berkompetisi secara sehat dalam meningkatkan prestasi belajar, juga memberikan fasilitas kepada peserta didik agar mampu menyajikan hasil kerja individual maupun kelompok. Selanjutnya pada fase konfirmasi, guru dapat memberikan umpan balik positif dan penguatan dalam bentuk isyarat, tulisan, lisan maupun reward. 
Ketika pembelajaran beriman kepada Malaikat Allah anak anakSD Negeri 2 Wates kesulitan dalam menyebutkan dan memahami makna beriman kepada malaikat Allah. Oleh karena itu kami mencoba untuk menggunakan beberapa metode dan strategi pembelajaran yang bisa menarik siswa belajar sebagaimana teori Gardner yang menyebutkan bahwa dalam proses belajar dibutuhkan suatu model pembelajaran yang variatif dan multiapproach. Dimana pembelajaran tersebut mampu membantu peserta didik mengembangkan kecerdasannya.

Berdasarkan permasalahan inilah maka kami mencoba menggunakan methode Smart game dalam penyajian materi pembelajaran ini. Karena metode ini menjadikan permainan dan nyanyian yang menyenangkan sebagai materi pembelajaran. Kami juga menggunakan pendekatan pembelajaran kooperatif learning karena pendekatan ini sangat sesuai untuk siswa sekolah dasar. Penggunaan metode ini untuk menghilangkan kejenuhan, memberikan perasaan gembira, belajar berbagi sekaligus mengajari peserta didik untuk berkolaborasi atau bekerjasama dengan yang lain.

Merujuk pada latar belakang di atas, maka rumusan masalah dalam penelitian ini adalah "Apakah menggunakan metode smart game dapat meningkatkan kemampuan menyebutkan nama-nama dan tugas-tugas malaikat Allah?". Tujuan dalam penelitian ini untuk membuktikan metode smart game mampu meningkatkan kemampuan perserta didik dalam menyebutkan nama-nama dan tugas-tugas malaikat Allah.

\section{Metode Penelitian}

Subyek penelitian ini adalah siswa kelas IV SD Negeri 2 Wates tahun pelajaran 2018/2019 dengan rincian 16 laki-laki dan 18 perempuan. Keadaan siswa kelas ini sangat beragam, dari segi prestasi belajarnya ada yang sangat menonjol dan ada sebagian siswa yang lambat/ kurang dalam keberhasilan belajarnya. Dikarenakan hanya beberapa peserta didik mengikuti TPA/madrasah Diniyah. Dalam penelitian ini melibatkan teman sejawat untuk menjadi observer.

Penelitian dilaksanakan bertahap dalam 3 siklus (pertemuan) pada tahun pelajaran 2018/2019 semester I mulai September s/d 


\section{eL-Tarbawj Fatkiyah}

Oktober 2018. Adapun jadwalnya sebagai berikut:

1. Siklus I (Rabu, 19 September 2018)

2. Siklus II (Rabu, 26 September 2018)

3. Siklus III (Rabu, 3 Oktober 2018)

Obyek tindakan pada penelitian ini:

1. Input (kondisi awal) yaitu hasil pretest

2. Pembelajaran, terdiri dari dari; Pengamatan terhadap guru(observing teachers) dalam aktivitas pembelajaran, pengamatan kelas (observing classroom) yaitu managemen kelas, pengamatan terhadap siswa(observing student) yaitu meliputi partisipasi dan kreatifitas siswa dalam belajar.

3. Output (hasil tindakan) berupa respon siswa terhadap kegiatan belajar mengajar dan nilai tes formatif pada setiap siklus, kriteria keberhasilan yang dicapai sebagai berikut:

$$
\begin{aligned}
& 89-100 \%=\text { sangat baik } \\
& 77-88,9 \%=\text { baik } \\
& 66-76,9 \%=\text { cukup } \\
& \leq 65.9 \%=\text { Perlu bimbingan }
\end{aligned}
$$

Penelitian ini merupakan penelitaian tindakan kelas (Class Action Research), yang bertujuan memperoleh hipotesis atau gambaran seberapa efektifnya menggunakan metode smart game dalam pembelajaran Pendidikan Agama Islam pada kompetensi dasar Iman kepada malaikat Allah. Model Kemmis dan Taggart digunakan dalam pelaksanaan pembelajaran dengan skema siklus spiral terdiri atas empat tindakan, diantaranya; rencana tindakan, implementasi tindakan, observasi tindakan, dan refleksi tindakan.

Adapun gambaran pelaksanaan penelitian ini adalah sebagai berikut: 


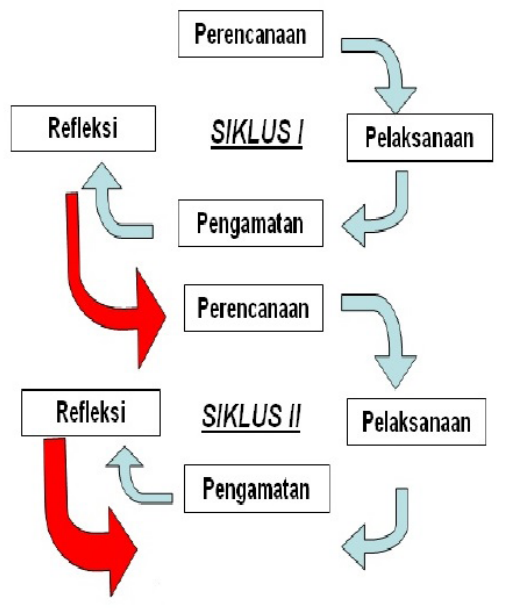

\section{Gambar 1. Pelaksanaan PTK (Penelitian Tindakan Kelas)}

Metode pengumpulan data menggunakan observasi dan dokumentasi. Observasi diabadikan dalam catatan observasi berkaitan dengan keaktifan guru dalam KBM (Kegiatan Belajar Mengajar), tingkat partisipasi siswa dan pengelolaan kelas. Dokumentasi untuk memantau keaktifan peserta didik, dirangkum dalam jurnal harian, dan evaluasi pembelajaran digunakan untuk mengetahui tingkat penguasaan siswa terhadap materi pembelajaran. Adapun analisis data dilakukan mitra kolaborator mulai dari awal penelitian, dan dikembangkan terus selama proses refleksi sampai penyusunan laporan. Sedang untuk menganalisis data dengan reduksi dan penyajian data, serta penarikan kesimpulan.

\section{Hasil Penelitian dan Pembahasan}

\section{A. Alur Penelitian}

Penelitian di SD Negeri 2 Wates Kulon Progo, dilaksanakan mengikuti alur berikut:

1. Perencanaan, meliputi penetapan materi pembelajaran Pendidikan Agama Islam dan penetapan alokasi waktu pelaksanaannya (September s.d. Oktober 2018) 
2. Pelaksanaan (Tindakan) meliputi seluruh proses kegiatan belajar mengajar menggunakan metode smart game

3. Observasi, meliputi dari kegiatan guru dalam KBM bersamaan dengan proses pembelajaran,diantaranya aktifitas guru dan partisipasi siswa dalam pembelajaran.

4. Refleksi, berupa hasil pembelajaran dan rencana perbaikan untuk siklus selanjutnya.

Penelitian ini melibatkan guru mata pelajaran (Agama) dan guru kelas, dalam kegiatan observasi dan menjadi reflektor pada saat penelitian sedang dilaksanakan. Hal ini untuk mengontrol validitas hasil penelitian.

\section{B. Keterangan Siklus}

Alur dalam penelitian ini melalui tahap perencanaan, tindakan, observasi, dan refleksi. Dijabarkan dalam bentuk tabel di bawah ini:

Tabel 1. Siklus I

\begin{tabular}{|c|c|c|c|c|}
\hline $\mathrm{NO}$ & PERENCANAAN & PELAKSANAAN & OBSERVASI & REFLEKSI \\
\hline 1 & 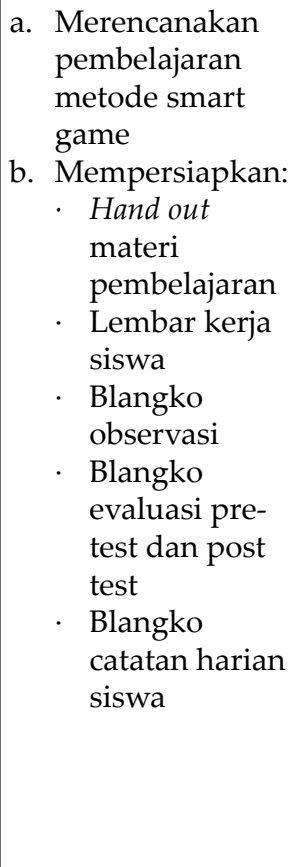 & 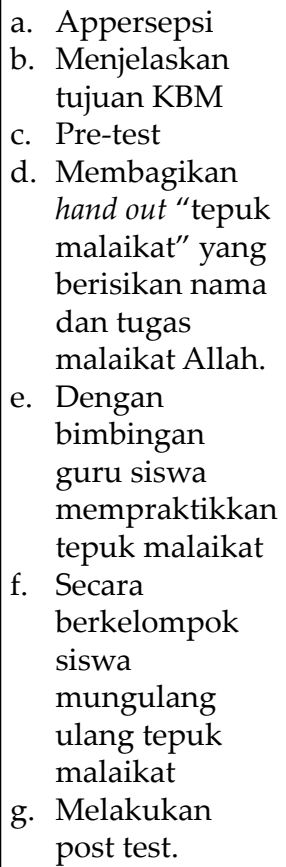 & $\begin{array}{l}\text { a. Mengamati } \\
\text { guru dalam } \\
\text { memulai } \\
\text { proses KBM } \\
\text { b. Mengamati } \\
\text { partisipasi } \\
\text { dan respon } \\
\text { siswa di } \\
\text { dalam kelas }\end{array}$ & \begin{tabular}{|ll} 
a. & Mencatat dan \\
& mengevaluasi \\
& hasil observasi \\
b. & Memperbaiki \\
& kelemahan \\
& yang \\
& ditemukan.
\end{tabular} \\
\hline
\end{tabular}


Ada beberapa kendala pada siklus I ini:

1. Siswa belum maksimal mempelajari nama-nama dan tugas-tugas malaikat Allah, dikarenakan pada siklus ini hanya dilakukan dua babak.

2. Ada beberapa siswa yang belum memahami tata cara bermain tepuk malaikat sehingga bingung dalam memberikan tanya jawab.

3. Siswa banyak yang enggan mendapatkan pasangan yang berbeda jenis kelamin.

4. Guru kurang mempersiapkan hand out tepuk malaikat, sehingga ditemukan siswa belum hafal pasangan jawabannya.

Setelah melihat kekurangan diatas, maka dilakukan perbaikan diantaranya; pelaksanaan smart game paling tidak 5 babak, sehingga siswa belajar secara maksimal. Agar pembelajaran selanjutnya lebih maksimal perbedaan jenis kelamin perlu diperhatikan. Demikian juga hand out tepuk malaikat dan tugasnya juga perlu diperhatikan agar tidak mengecewakan siswa.

Tabel 2. Siklus II

\begin{tabular}{|c|c|c|c|c|}
\hline NO & PERENCANAAN & PELAKSANAAN & OBSERVASI & REFLEKSI \\
\hline 2 & $\begin{array}{l}\text { a. Membuat } \\
\text { rencana } \\
\text { pembelajaran } \\
\text { dengan } \\
\text { didasarkan pada } \\
\text { siklus I } \\
\text { b. Mempersiapkan: } \\
\text {. Soal dan } \\
\text { beberapa } \\
\text { dokumen } \\
\text { yang hampir } \\
\text { sama dengan } \\
\text { dokumen } \\
\text { pada siklus I. } \\
\text {. Hand out } \\
\text { tepuk } \\
\text { malaikat dan } \\
\text { tugasnya } \\
\text { (smart game) }\end{array}$ & $\begin{array}{l}\text { a. Appersepsi } \\
\text { b. Menjelaskan } \\
\text { tujuan KBM } \\
\text { c. Dengan } \\
\text { bimbingan } \\
\text { guru, siswa } \\
\text { melakukan } \\
\text { tepuk malaikat } \\
\text { d. Siswa dibagi } \\
\text { menjadi } \\
\text { beberapa } \\
\text { kelompok, } \\
\text { kemudian } \\
\text { dalam } \\
\text { kelompok } \\
\text { masing-masing } \\
\text { melakukan } \\
\text { tepuk malaikat }\end{array}$ & \begin{tabular}{|l} 
a. \\
keaktifan \\
siswa dalam \\
mengikuti \\
pembelajaran \\
b. Mengamati \\
guru dalam \\
mengelola \\
kelas maupun \\
mengaktifkan \\
kegiatan \\
pembelajaran \\
c. Mengamati \\
respon \\
siswa dalam \\
mengikuti \\
pembelajaran
\end{tabular} & \begin{tabular}{|l} 
a. \\
Mencatat dan \\
mengevaluasi \\
hasil observasi \\
b. Menganalisiss \\
hasil KBM \\
c. Memperbaiki \\
kelemahan \\
yang \\
ditemukan.
\end{tabular} \\
\hline
\end{tabular}


Ada beberapa kendala pada siklus II ini:

1. DalammetodeSmart Games, siswa dituntutuntukmampumenghafal nama dan tugas-tugas malaikat. Setelah mempraktikkannya dengan tepuk (games), didapati siswa yang belum menghafal dengan sempurna baik nama maupun tugas-tugas malaikan, sehingga hal tersebut menghambat games. mempengaruhipermainan.

2. Siswa masih keliru dalam memadukan nama malikat dengan tugasnya. Kekeliruan yang sering terjadi ada pada nama dan tugas malaikat Izrail \& Israfil, Rakib \& Atid, serta Malik \& Ridawan.

Namun pada siklus ini, siswa tidak berkenan mendapatkan pasangan games yang berbeda gender. Siswa juga berangsur-angsur berusaha menghafalkan nama dan tugas malaikat

Beberapa kekurangan di atas, disimpulkan sebagai bentuk perbaikan diantaranya; guru secara intens mendampingi hafalan siswa terkait nama dan tugas malaikat dengan terus me-recall tepuk malaikat.

Tabel 3. Siklus III

\begin{tabular}{|c|c|c|c|c|}
\hline NO & PERENCANAAN & PELAKSANAAN & OBSERVASI & REFLEKSI \\
\hline 3 & \begin{tabular}{|l|} 
a. \\
Membuat \\
rencana \\
pembelajaran \\
dengan \\
didasarkan pada \\
siklus II \\
b. Mempersiapkan: \\
. Soal dan \\
beberapa \\
dokumen \\
yang hampir \\
sama dengan \\
dokumen pada \\
siklus II \\
Hand out tepuk \\
malaikat dan \\
tugasnya (smart \\
game)
\end{tabular} & $\begin{array}{l}\text { a. Appersepsi } \\
\text { b. Menjelaskan } \\
\text { tujuan KBM } \\
\text { c. Dengan } \\
\text { bimbingan } \\
\text { guru, siswa } \\
\text { melakukan } \\
\text { tepuk malaikat } \\
\text { d. Siswa dibagi } \\
\text { menjadi } \\
\text { beberapa } \\
\text { kelompok, } \\
\text { kemudian } \\
\text { dalam kelompok } \\
\text { masing-masing } \\
\text { melakukan } \\
\text { tepuk malaikat } \\
\text { e. Tepuk } \\
\text { malaikat yang } \\
\text { dipraktikkan } \\
\text { adalah dengan } \\
\text { model tanya } \\
\text { jawab }\end{array}$ & $\begin{array}{l}\text { a. Mengamati } \\
\text { keaktifan, } \\
\text { kreativitas, } \\
\text { dan } \\
\text { partisipasi } \\
\text { siswa dalam } \\
\text { mengikuti } \\
\text { pembelajaran } \\
\text { b. Mengamati } \\
\text { guru dalam } \\
\text { mengelola } \\
\text { kelas maupun } \\
\text { mengaktifkan } \\
\text { kegiatan } \\
\text { pembelajaran } \\
\text { c. Mengamati } \\
\text { respon } \\
\text { siswa dalam } \\
\text { mengikuti } \\
\text { pembelajaran }\end{array}$ & \begin{tabular}{|l} 
a. \\
mencatat dan \\
hasil observaluasi \\
b. Menganalisiss \\
hasil KBM \\
c. Memperbaiki \\
kelemahan \\
yang \\
ditemukan.
\end{tabular} \\
\hline
\end{tabular}




\begin{tabular}{|l|l|l|l|l|}
\hline NO & PERENCANAAN & PELAKSANAAN & OBSERVASI & REFLEKSI \\
\hline & & f. Sebagai & & \\
& & bahan refleksi & & \\
& pembelajaran & & \\
dengan guru & & & \\
& & mendampingi & & \\
& siswa dalam & & \\
& menghafal & & \\
& nama dan & & \\
& tuga malaikat, & & \\
& dengan me-recall & & \\
& hafalan melalui & & \\
& tepuk malaikat & & \\
& g. Dst & & \\
& &
\end{tabular}

Pada siklus III ini tidak menunjukkan hambatan atau kekurangan yang sangat berpengaruh. Hanya sedikit ditemukan siswa yang masih terbalik-balik antara nama dan tugas malaikat sebagaimana dalam siklus II. Tetapi kemudian dibimbing oleh guru dalam penyebutan nama dan tugas malaikat agar tidak keliru.

Dalam pelaksanaan tiga siklus penelitian tindakan kelas ini, subjek penelitian hadir secara keseluruhan mulai pada siklus pertama hingga ketiga, dengan demikian subjek penelitian menjadi 34 siswa, 16 laki-laki dan 18 perempuan.

\section{Analisis Data}

Berikut data hasil pre-test dan tes tulis;

Tabel 4. Daftar Nilai Pre-Test, Siklus I, II, dan III

\begin{tabular}{|c|c|c|c|c|c|c|c|c|c|}
\hline \multirow{2}{*}{ NO } & \multirow{2}{*}{$\begin{array}{c}\text { NAMA } \\
\text { SISWA }\end{array}$} & \multicolumn{2}{|c|}{ PRE-TEST } & \multicolumn{2}{c|}{ SIKLUS I } & \multicolumn{2}{c|}{ SIKLUS II } & \multicolumn{2}{c|}{ SIKLUS III } \\
\hline 1. & SKOR & SILAI & SKOR & NILAI & SKOR & NILAI & SKOR & NILAI \\
\hline 2. & S2 & 7 & 70 & 7 & 70 & 8 & 80 & 9 & 90 \\
\hline 3. & S3 & 6 & 60 & 7 & 70 & 8 & 80 & 9 & 90 \\
\hline 4. & S4 & 5 & 50 & 5 & 70 & 8 & 80 & 8 & 80 \\
\hline 5. & S5 & 8 & 80 & 8 & 80 & 9 & 90 & 9 & 90 \\
\hline 6. & S6 & 6 & 60 & 7 & 70 & 8 & 80 & 9 & 90 \\
\hline 7. & S7 & 8 & 80 & 8 & 80 & 9 & 90 & 10 & 100 \\
\hline 8. & S8 & 4 & 40 & 5 & 50 & 6 & 60 & 7 & 70 \\
\hline 9. & S9 & 8 & 80 & 8 & 80 & 9 & 90 & 10 & 100 \\
\hline 10. & S10 & 8 & 80 & 9 & 90 & 10 & 100 & 10 & 100 \\
\hline 11. & S11 & 7 & 70 & 8 & 80 & 9 & 90 & 10 & 100 \\
\hline 12. & S12 & 7 & 70 & 8 & 80 & 9 & 90 & 10 & 100 \\
\hline 13. & S13 & 7 & 70 & 8 & 80 & 9 & 90 & 10 & 100 \\
\hline 14. & S14 & 6 & 60 & 7 & 70 & 8 & 80 & 9 & 90 \\
\hline
\end{tabular}




\begin{tabular}{|c|c|c|c|c|c|c|c|c|c|}
\hline \multirow{2}{*}{ NO } & NAMA & \multicolumn{2}{|c|}{ PRE-TEST } & \multicolumn{2}{c|}{ SIKLUS I } & \multicolumn{2}{c|}{ SIKLUS II } & \multicolumn{2}{c|}{ SIKLUS III } \\
\cline { 3 - 9 } & SISWA & SKOR & NILAI & SKOR & NILAI & SKOR & NILAI & SKOR & NILAI \\
\hline 15. & S15 & 4 & 40 & 5 & 50 & 6 & 60 & 7 & 70 \\
\hline 16. & S16 & 7 & 70 & 8 & 80 & 9 & 90 & 9 & 90 \\
\hline 17. & S17 & 8 & 80 & 9 & 90 & 10 & 100 & 9 & 100 \\
\hline 18. & S18 & 8 & 80 & 9 & 90 & 9 & 90 & 10 & 100 \\
\hline 19. & S19 & 8 & 80 & 9 & 90 & 9 & 90 & 10 & 100 \\
\hline 20. & S20 & 8 & 80 & 9 & 90 & 10 & 100 & 10 & 100 \\
\hline 21. & S21 & 5 & 50 & 6 & 60 & 5 & 70 & 8 & 80 \\
\hline 22. & S22 & 4 & 40 & 4 & 40 & 7 & 60 & 7 & 70 \\
\hline 23. & S23 & 8 & 80 & 8 & 80 & 9 & 90 & 10 & 100 \\
\hline 24. & S24 & 8 & 80 & 8 & 80 & 8 & 90 & 10 & 100 \\
\hline 25. & S25 & 7 & 70 & 7 & 70 & 9 & 90 & 9 & 90 \\
\hline 26. & S26 & 7 & 70 & 8 & 80 & 5 & 80 & 9 & 90 \\
\hline 27. & S27 & 6 & 60 & 7 & 70 & 9 & 80 & 8 & 80 \\
\hline 28. & S28 & 6 & 60 & 7 & 70 & 9 & 80 & 8 & 80 \\
\hline 29. & S29 & 7 & 70 & 7 & 70 & 5 & 80 & 8 & 80 \\
\hline 30. & S30 & 7 & 70 & 7 & 70 & 7 & 70 & 9 & 90 \\
\hline 31. & S31 & 5 & 50 & 6 & 60 & 6 & 70 & 8 & 80 \\
\hline 32. & S33 & 8 & 80 & 8 & 80 & 9 & 90 & 10 & 100 \\
\hline 33. & S34 & 5 & 50 & 6 & 60 & 5 & 70 & 8 & 80 \\
\hline 34. & S35 & 4 & 40 & 4 & 40 & 7 & 60 & 7 & 70 \\
\hline IUMLAH & 215 & 2150 & 234 & 2340 & 236 & 2650 & 286 & 2870 \\
\hline RATA-RATA & 6.71 & 67.18 & 7.31 & 73.12 & 7.37 & 82.81 & 8.93 & 89.68 \\
\hline
\end{tabular}

Adapun rekapitulasi perbandingan dan peningkatan keberhasilan pada pre-test, siklus I, II, dan III sebagai berikut:

Tabel 5. Rekapitulasi Persentase dan Nilai Pre-Test, Siklus I, II, dan III

\begin{tabular}{|c|c|c|c|c|c|c|c|c|c|c|c|c|c|}
\hline \multirow[b]{2}{*}{$\mathrm{NO}$} & \multirow[b]{2}{*}{ Kategori } & \multicolumn{3}{|c|}{ PRE-TEST } & \multicolumn{3}{|c|}{ SIKLUS I } & \multicolumn{3}{|c|}{ SIKLUS II } & \multicolumn{3}{|c|}{ SIKLUS III } \\
\hline & & $\begin{array}{c}\text { Jml } \\
\text { siswa }\end{array}$ & $\%$ & $\begin{array}{l}\text { Rata- } \\
\text { rata }\end{array}$ & $\begin{array}{c}\text { Jml } \\
\text { siswa }\end{array}$ & $\%$ & $\begin{array}{l}\text { Rata- } \\
\text { rata }\end{array}$ & $\begin{array}{l}\mathrm{Jml} \\
\text { siswa }\end{array}$ & $\%$ & $\begin{array}{c}\text { Rata- } \\
\text { rata }\end{array}$ & $\begin{array}{c}\mathrm{Jml} \\
\text { siswa }\end{array}$ & $\%$ & $\begin{array}{c}\text { Rata- } \\
\text { rata }\end{array}$ \\
\hline 1 & \begin{tabular}{|l|} 
Baik Sekali \\
$89-100$
\end{tabular} & 0 & $0 \%$ & \multirow[t]{6}{*}{67.19} & 5 & 14.17 & \multirow[t]{6}{*}{73.12} & 16 & $50 \%$ & \multirow[t]{6}{*}{82.81} & 22 & 64.70 & \multirow[t]{6}{*}{89.69} \\
\hline \multirow[t]{2}{*}{2} & Baik & \multirow[t]{2}{*}{11} & \multirow[t]{2}{*}{$32.3 \%$} & & \multirow[t]{2}{*}{11} & \multirow[t]{2}{*}{32.35} & & \multirow[t]{2}{*}{9} & \multirow[t]{2}{*}{$24.46 \%$} & & \multirow[t]{2}{*}{7} & \multirow[t]{2}{*}{20.59} & \\
\hline & $77-89$ & & & & & & & & & & & & \\
\hline \multirow[t]{2}{*}{3} & Cukup & \multirow[t]{2}{*}{10} & \multirow[t]{2}{*}{$29.4 \%$} & & \multirow[t]{2}{*}{10} & \multirow[t]{2}{*}{29.41} & & \multirow[t]{2}{*}{5} & \multirow[t]{2}{*}{14.17} & & \multirow[t]{2}{*}{5} & \multirow[t]{2}{*}{14.17} & \\
\hline & $66-77$ & & & & & & & & & & & & \\
\hline 4 & $\begin{array}{l}\begin{array}{l}\text { Perlu } \\
\text { bimbingan }\end{array} \\
\leq 66\end{array}$ & 13 & $38.23 \%$ & & 8 & $23.53 \%$ & & 4 & $11.76 \%$ & & & & \\
\hline \multicolumn{2}{|r|}{$J U M L A H$} & 34 & $100 \%$ & 67.19 & 34 & $100 \%$ & 73.12 & 34 & & 82.81 & 34 & $100 \%$ & 89.69 \\
\hline \multicolumn{2}{|r|}{ Rata rata } & & & & & & & & & & & & \\
\hline
\end{tabular}

Melihat data diatas dapat diketahui bahwa nilai rata rata saat pretest adalah $67,19 \%$ artinya bahwa pemahaman anak terhadap materi pembelajaran nama nama dan tugas malaikat Allah masih dalam katagore perlu bimbingan. Karena ada 11 anak kategori baik,(32,3\%), 
yang mendapat nilai cukup ada 10 anak (29.4\%) dan yang 13 anak $(38.23 \%)$ masih dalam kategori perlu bimbingan.

Kemudian dilakukan tindakan siklus I nilai rata ratanya naik menjadi 73.12.disiklus I ini sudah tergambar peningkatan kemampuan anak terhadap materi pembelajaran. Yakni 5 anak mendapatkan nilai amat baik(14.17\%), 11 anak mendapatkan nilai baik (32.35\%) ada 10 anak mendapatkan nilai cukup (29.41\%) dan 8 anak mendapatkan nilai perlu bimbingan (22\%)

Pada siklus kedua rata-rata kelas meningkat lagi menjadi 83 . ini membuktikan bahwa pemahaman anak semakin meningkat lagi karena anak yang medapatkan nilai baik sekali ada 11 anak (32\%) mendapatkan nilai baik ada 10 anak (30\%) yang mendapatkan nilai cukup ada 6 anak $(17 \%)$ dan yang perlu mendapatkan bimbingan ada 7 anak.(21\%).

Segala tindakan yang dilakukan pada siklus III menunjukkan hasil yang memuaskan. Pemahaman siswa meningkat semakin baik dengan ata-rata kelas 89.69. Sebanyak 20 anak (59\%) mendapatkan nilai baik sekali, kategori baik 6 anak (17\%), yang kategori cukup 4 anak(17\%) dan yang masih perlu bimbingan yaitu siswa yang belum lancar menulis dan membaca ada 6 anak (17\%). Data tersebut menunjukkan bahwa pemahaman siswa terhadap materi mempengaruhi kemampuan membaca siswa.

Perbandingan perolehan nilai pre-test, siklus I, II, dan siklus III digambarkan dalam bentuk diagram sebagai berikut;

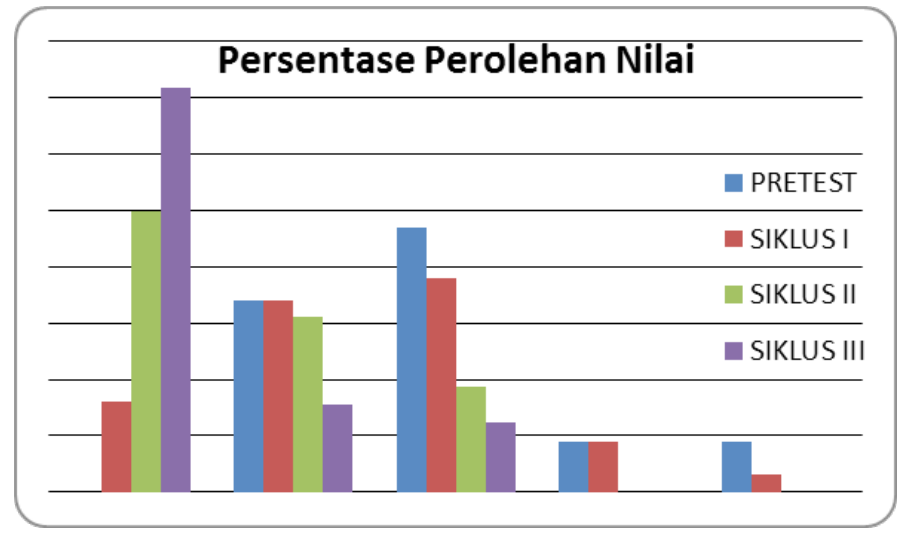

Grafik 1. Persentase Perolehan Nilai 
Capaian hasil nilai rata-rata siswa sebagai berikut:

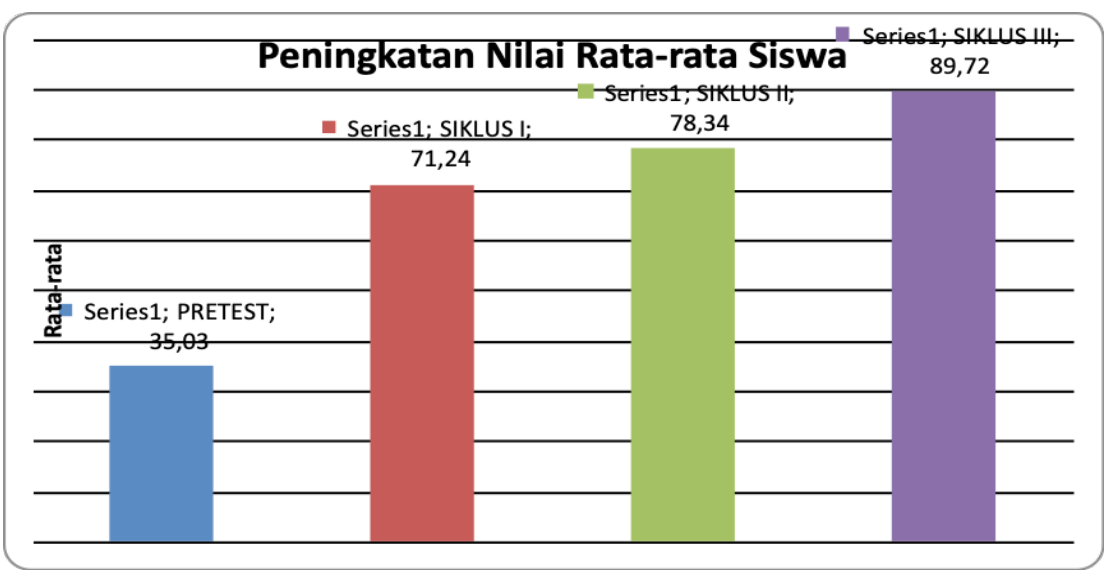

Grafik 2. Peningkatan Nilai Rata-Rata Siswa

Catatan harian siswa terhadap pembelajaran disimpulkan dalam satu kesan yang sangat dominan, yaitu kesan positif, sedangkan kesan yang lainnya yaitu negatif dan biasa. Kesan positif merupakan kelompok siswa yang tertarik dengan pembelajaran smart games, sedang kesan negatif bagi siswa yang kurang tertarik terhadap pembelajaran, dan kesan biasa bagi siswa yang tidak menaruh ketertarikan yang dominan maupun ketidak tertarikan yang dominan. Adapun gambaran grafiknya berikut ini:

Tabel 6. Kesan Siswa pada Pembelajaran Metode Smart Game

\begin{tabular}{|l|c|c|c|c|c|c|}
\hline \multirow{2}{*}{ Kategori } & \multicolumn{6}{|c|}{ Kesan siswa } \\
\cline { 2 - 7 } & SIKLUS I & $\%$ & SIKLUS II & $\%$ & SIKLUS III & $\%$ \\
\hline POSITIF & 34 & 100 & 34 & 100 & 34 & 100 \\
\hline BIASA & - & - & - & - & - & - \\
\hline NEGATIF & - & - & - & - & - & - \\
\hline
\end{tabular}


Data di atas dikonversikan dalam bentuk grafik berikut;

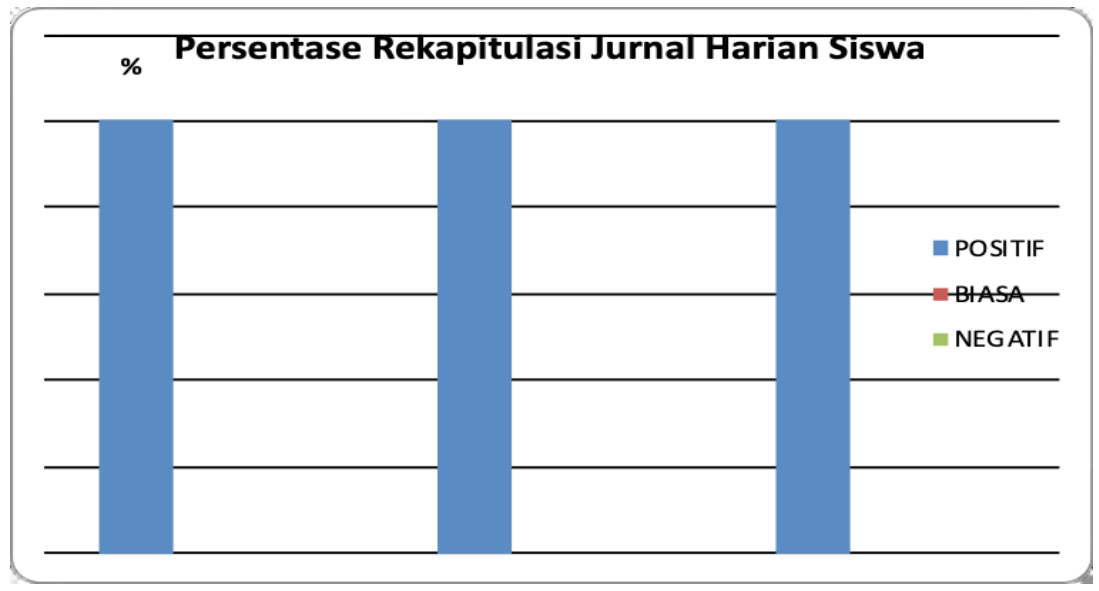

Grafik 3. Persentase Catatan Harian Siswa

Grafik diatas menggambarkan bahwa pembelajaran dengan menggunakan smart games dapat meningkatkan respon positif dari siswa. Bahkan rata-rata respon siswa diketiga siklus tersebut adalah $100 \%$.

\section{Pembahasan Hasil Penelitian}

1. Sudut Pandang Kualitatif

Hasil catatan siswa, rata-rata respon positif terhadap penggunaan metode smart games pada pembelajaran nama-nama dan tugastugas malaikat mencapai $100 \%$.

2. Sudut Pandang Kuantitatif

Setelah diadakan tindakan siklus I, siklus II dan siklus III dengan menggunakan metode smart Games siswa lebih mudah menghafal dan mampu menyebutkan nama dan tugas-tugas malaikat.

Bila dikonversikan ke dalam kategori keberhasilan yang peneliti tetapkan sebagai berikut:

$89-100 \%$; sangat baik

$77-89 \%$; baik

$66-77 \%$; cukup

$<66 \%$; Perlu mendapat bimbingan 


\section{eL-Tarbawj Fatkiyah}

Berarti dapat disimpulkan bahwa pembelajaran yang menggunakan metode Smart Games sangat baik hasilnya dan cocok digunakan pada pembelajaran nama dan tugas-tugas malaikat.

\section{Kesimpulan}

Pembelajaran nama dan tugas-tugas malaikat Allah dapat lebih meningkat dengan menggunakan metode smart games. Dibuktikan dari peningkatan perolehan nilai pretest, siklus I, II, dan III dengan curva peningkatan yang sangat signifikan. Begitu halnya dengan respon siswa terhadap pelaksanaan pembelajaran ini sangat baik.

\section{Saran}

Pembelajaran Pendidikan Agama Islam di tingkat SD dapat menggunakan metode smart games untuk memvariasi metode pembelajaran. Metode ini mampu menjadikan pemebelajaran menjadi aktif, menyenangkan, kooperatif. Metode ini juga mampu meningkatkan kompetensi dan ketuntasan pembelajaransiswa pada pembelajaran Pendidikan Agama Islam.

Kepada peneliti selanjutnya mampu mengeksplorasi materi, jenjang, dan subjek penelitian yang lebih luas lagi.

\section{Daftar Pustaka}

Azis, Rahmat. Penggunaan Model Pembelajaran Kooperatif dan Kompetitif dalam mengembangkan Kreatifitas. www.azirahma. blogspot.com, diakses 08 Januari 2009, pkl 14.42 WIB. . 2006. Panduan Penyusunan Kurikulum Tingkat Satuan Pendidikan Jenjang Pendidikan dasar dan Menengah. Jakarta: Badan Standar Nasional Pendidikan.

. 2016. Peraturan Mendikbud No 22 Tahun 2016 Tentang Standar Proses Untuk Satuan Pendidikan Dasar Sekolah Dasar/Madrasah Ibtidaiyah. Jakarta: Badan Standar Nasional Pendidikan.

Departemen Pendidikan Nasional. 2006. Peraturan Mendiknas No 22 Tahun 2006 Tentang Standar Isi Dan Standar Kelulusan Untuk Satuan Pendidikan Dasar Sekolah Dasar/Madrasah Ibtidaiyah. Jakarta: Pustaka Candra. 
Departemen Pendidikan Nasional. Konsep PAKEM. www. akhmadsudrajat.wordpress.com, diakses pada 20 Desember 2008, pk1 12.06 WIB.

Holil, Anwar. . Model Pembelajaran Kooperatif. www.anwarholil. blogspot.com, diakses 26 Januari 2009, pkl 21.42 WIB.

Karlina, Ina. - Pembelajaran Kooperatif (Cooperative Learning) sebagai salah satu Strategi Membangun pengetahuan Siswa. www. gooogle.co.id, diakses pada 26 Januari 2009, pkl 22.00 WIB.

Kurniawan, Yudha. 2008. Smart games for Kids. Jakarta: Wahyu Media. Masoffa.__. Perbedaan Pembelajaran Kooperataif dan Pembelajaran Konvensional. www.masoffa.wordpress.com, diakses pada 26 Januari 2009, pkl 15.45 WIB.

Nusridik, Yahya.___ Kumpulan Metode Pembelajaran. wwwapadefinisinya.blogspot.com, diakses pada 26 Januari 2009, pkl 19.30 WIB.

Shihab, M Quraisy. 1996. Lentera Hati. Bandung: Penerbit Mizan.

Slavin, Robert E. 2008. Cooperative Learning, Teori, Riset dan Praktik, Terj: Nurulita. Bandung: Nusa Media.

Arikunto, Suharsimi dkk. 2008. Penelitian Tindakan Kelas. Jakarta: Bumi Aksara.

Syurfah, Ariany. 2007. Multiple Inteligences for Islamic Teaching. Bandung: Syamil Publising.

Tarmizi.___. Pembelajaran Kooperatif "Make a Mactch". www.tarmizi. wordpress.com, diakses pada 26 Januari 2009, pkl. 20.02 WIB.

Tim Ipotes. _... Metode Pembelajaran Kooperatif . www.ipotes. wordpress.com, diakses 26 Januari 2009, pkl 21.22 WIB.

Tim Learning with Me. . Pembelajaran. www learning-with-meblogspot.com, diakses pada 26 Januari 2009. Pkl 21.45 WIB.

Tim Pembelajaran Guru. Inovasi Pembelajaran Mipa Di Sekolah Dan Alternative Implementasinya _ Cooperative Learning (Pembelajaran Kooperatif). www.pembelajaranguru.wordpress, diakses pada 26 Januari 2009. Pkl 21.55 WIB. 